\title{
Effect of surface roughness and lubrication on the friction coefficient in deep drawing processes of aluminum alloy aa1100 with fem analysis
}

Luis Fernando Folle ${ }^{1}$, Lirio Schaeffer ${ }^{2}$

\author{
${ }^{1}$ Master Program in Design, UniRitter, Porto Alegre, Rio Grande do Sul, Brazil. \\ e-mail: luis_folle@uniritter.edu.br \\ ${ }^{2}$ Department of Metallurgy - Federal University of Rio Grande do Sul, UFRGS, Av. Bento Gonçalves, 9500, Porto \\ Alegre, Rio Grande do Sul, Brazil. \\ e-mail: schaefer@ufrgs.br
}

\begin{abstract}
Friction between the interface workpiece and tooling has considerable importance in sheet metal forming operations; an accurate description of the friction is necessary to analyze and design new workpieces and tooling. This work suggests a methodology to determine and evaluate the mean coefficient of friction (COF) using the Finite Element Method (FEM) through Dynaform for the aluminum alloy AA1100. The results indicate that this methodology is consistent with reality. It is also observed that the software tends to diverge from the measured results because the software considers the COF to be constant along the process. Despite this trend, the greatest distance between the maximum drawing force given by the measurement and the numeric simulation was not high: it was approximately $6 \%$. Workpiece strain measurements were collected to compare with the numerical simulation results, and it was observed that they are generally in agreement.
\end{abstract}

Keywords: coefficient of friction; Swift cup test; FE analysis; deep drawing process; Part Design.

\section{INTRODUCTION}

Recently, increasing the knowledge about the friction in sheet metal forming operations has been a priority. Many methods of determining the coefficient of friction (COF) have been studied, and the current most commonly used method is the bending under tension test (BUT). In this test, a strip is bent and slid through a pin with a specific radius $(\mathrm{R})$ to mimic the same conditions of the die radius in deep drawing. Lee et al. [1] used this test to study the relationships among surface roughness, lubricant film thickness and the COF. Ceretti et al. [2] investigated the variation of COF with respect to the speed, pressure and temperature of the blank using the pin-on-disk test.

The BUT test, however, requires specific equipment built for this purpose; there is no such device manufacturer. Other authors like Darendeliler et al. [3] used the simulation program to evaluate the COF through simpler techniques, such as tribological tests only in the sheets, like the pin-on-disk test.

Kim et al. [4] studied the performance of five lubricants with respect to the blank-holder force, punch force, flange perimeter and changes in the surface topography and roughness. The COF was obtained using PAM-STAMP software; in addition, the measured and simulated results were compared using this software.

Murakawa and Takeuchi [5] used DLC coating (Diamond-like carbon) on a ball that was slid against an aluminum sheet, and the COF was measured. Guillon et al. [6] used other friction tests similar to that of Murakawa and Takeuchi; however, the slide tool had a cylindrical shape, and the authors performed surface topography analysis with different tool coatings.

FRATINI et al. [7] analyzed the effect of some finishes of the pin surface together with the application of different lubricants. He found that a chrome surface alone is not enough to greatly reduce friction, it is necessary to apply a lubricant and the lowest friction was achieved with the use of Teflon. Other important information was obtained by HAO et al. [8] which varied the stamping speed, the lubricant employed and the material of the pin with respect to the deformation of the sheet. Similarly, LOVELL et al. [9] analyzed the coefficient of friction in relation to the use of oils that do not attack the environment and found that canola oil with a mixture of boric acid presents good friction results. In the work of ANDREASEN et al. [10], it was found that the torque measured on the pin during the test is more sensitive to 
friction than the forces of actuation and counter-tension.

The various studies done with friction did not attempt to correlate real tests, numerical simulation, and analytical calculations. Articles focus on just one subject or another. Thus, the objective of this paper is to use Panknin's [11] analytical equations to determine the value of the friction coefficient by comparing it with a real test and uses it as input data in the LS-Dynaform Finite Element (FE) software. With the simulation done, the force-displacement curve of the punch will be obtained and compared with the real test to verify the level of divergence that the friction can give.

\section{EXPERIMENTAL SETUP}

A cylindrical cup was used as the workpiece geometry, and the plot of punch force versus punch displacement was used to compare the true measurements and the simulation. The geometry was the same as that of the Swift cup test, which was described by Mielnik [12]. This test emulates the deep drawing process because there is tensile stress in the radial direction and compressive stress in the circumferential direction. The tools used in the Swift test include a cylindrical punch, blank-holder and die. The dimensions are shown in Figure 1. The punch is then forced against the blank until the deep drawing ends or the material cracks.

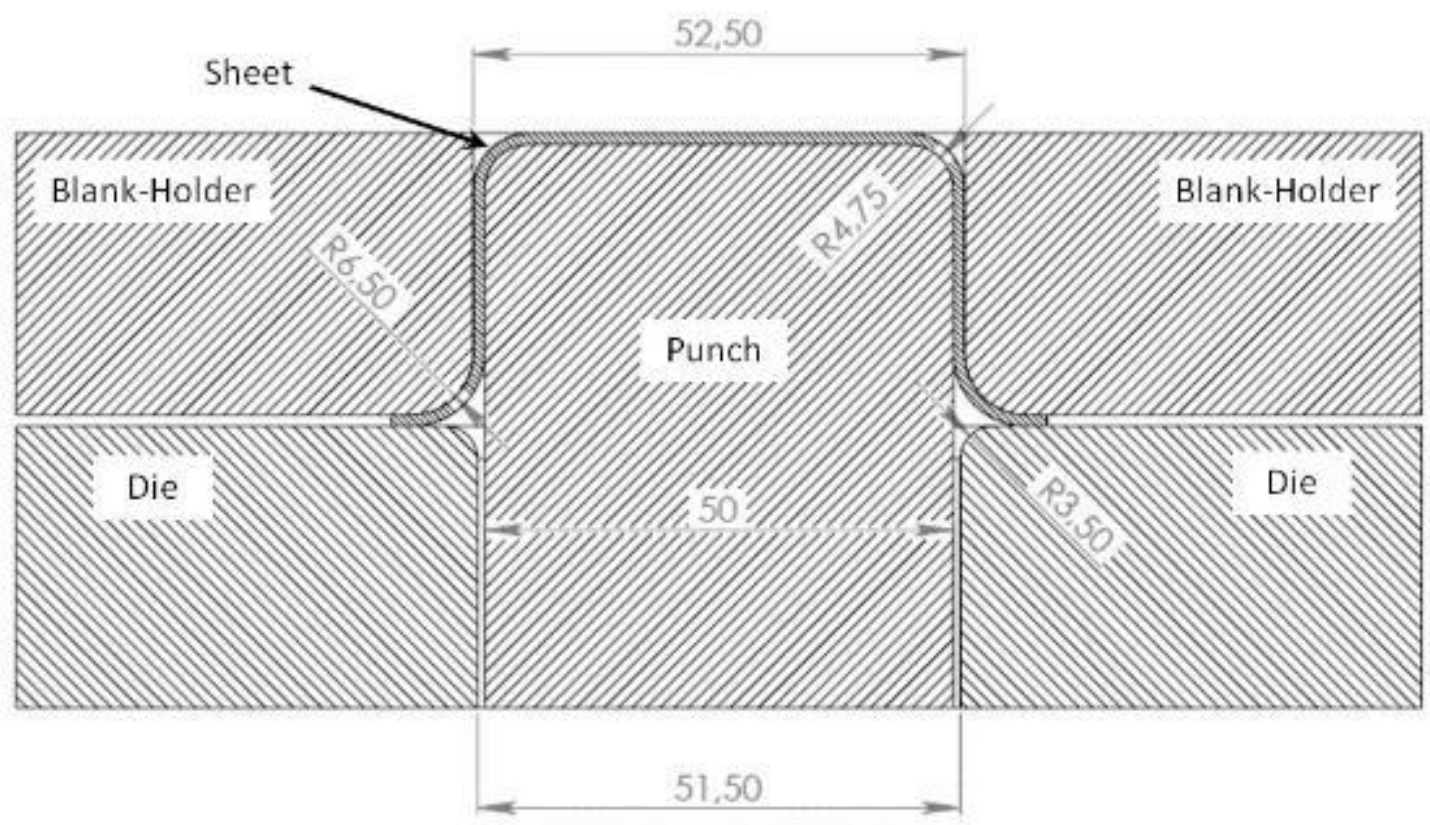

Figure 1: Cut view of the Shift cup test (dimensions in $\mathrm{mm}$ ).

\subsection{Surface conditions applied}

To obtain different COF between tools and the sheet in the deep drawing test, the following methodology was used. Surface roughness variation of the die and blank-holder was induced by applying sandpaper with a specific grit in addition to four lubricants. The unique varying parameters were surface finishing and lubricants; all other parameters remained constant.

The sandpaper grit used was 220, 400 and 1200. The application methodology consisted in adapting the matrices in a machining lathe with constant speed of rotation in the spindle ("chuck"). Sandpaper applications were made from the inside out of the dies in just a single pass and slow enough to ensure a visible change in finish texture. The sandpapers were applied beginning with the largest and continuing to the smallest grit to remove the previous surface finish; for example, if it was necessary to use the 1200 sandpaper, then the 220 and 400 sandpapers were applied in sequence.

For these finishes, the average ( $\mathrm{Ra}$ ) and maximum (Rmax) roughness of the surfaces were evaluated after the application of each final sandpaper according to the ISO standard. The results are shown in table 1 in $\mu \mathrm{m}$ for an average of 5 measurements. The cut-off parameter adopted was $0.8 \mathrm{~mm}$. 
Table 1: Roughness measures for each finish.

\begin{tabular}{l|l|l|l|l|l|l}
\hline SANDPAPER & \multicolumn{2}{|c|}{1200} & \multicolumn{2}{c|}{$\mathbf{4 0 0}$} & \multicolumn{2}{c}{220} \\
\hline ROUGHNESS & $\mathbf{R}_{\mathbf{A}}$ & $\mathbf{R}_{\text {MAX }}$ & $\mathbf{R}_{\mathbf{A}}$ & $\mathbf{R}_{\text {MAX }}$ & $\mathbf{R}_{\mathbf{A}}$ & $\mathbf{R}_{\text {MAX }}$ \\
\hline Upper Die & 0,20 & 2,36 & 0,32 & 2,98 & 0,32 & 2,56 \\
\hline Lower Die & 0,30 & 2,38 & 0,20 & 2,18 & 0,27 & 2,64 \\
\hline
\end{tabular}

Analyzing table 1, it can be observed that the roughnesses measured in all finishes applied had very close values. This is in agreement with the literature, since the values of Ra between 0,4 and $0,2 \mu \mathrm{m}$ present finishing from the conventional machining until the polishing operation.

The roughnesses $\mathrm{Ra}$ and Rmax, measured at the punch, were 0.11 and $1.46 \mu \mathrm{m}$ respectively and no sandpaper was applied, ie these values remained constant during all the measurements. This was done due to the fact that, for the geometry used, the punch comes into contact with the sheet only in the center of the sheet, where there is practically no deformation of the sheet and the slip between the surfaces is almost zero.

The lubricants used in this work are mineral based oils that are commonly used by sheet metal forming industries. The lubricants were labeled as the following: lub F, lub L, lub O and lub S. Two other lubricants tested included grease and a $0.09 \mathrm{~mm}$ thick sheet of Teflon. The condition without lubricant (the dry condition) was also tested, and the surface finish applied in this case was with 1200 sandpaper.

The lubricants were applied in abundance on the two sides of the blank and were not applied to the tools. The abundance of lubricant in the blank ensures that the tools will be well lubricated. Acetone was used to remove the remaining lubricant before applying other lubricants, and it was used on all of the tools.

\subsection{Mechanical property of the blank}

The properties of the material used in this work, AA1100 aluminum, or commercially pure aluminum, are described in Table 2.

Table 2: Properties used to define the material of the blank.

\begin{tabular}{l|l|l}
\hline MATERIAL PROPERTY & VALUE & UNITY \\
\hline Density & 2.7 & $\mathrm{~g} / \mathrm{cm} 3$ \\
\hline Young's modulus & 69000 & $\mathrm{MPa}$ \\
\hline Poisson ratio & 0.33 & \\
\hline Strain hardening exponent $(\mathrm{n})$ & 0.09 & \\
\hline Strain hardening coefficient $(\mathrm{C})$ & 196 & $\mathrm{MPa}$ \\
\hline Anisotropy $\left(0^{\circ}\right)$ & 0.82 & \\
\hline Anisotropy $\left(45^{\circ}\right)$ & 0.76 & \\
\hline Anisotropy $\left(90^{\circ}\right)$ & 0.81 & \\
\hline Yield strength & 124 & $\mathrm{MPa}$ \\
\hline Yield strain & 0.2 & $\%$ \\
\hline
\end{tabular}

\subsection{Forming Limit Curve}

To determine the Forming Limit Curve (FLC), the Nakajima test was used with a hemispheric punch radius of $50 \mathrm{~mm}$. A cushion of 6-mm-thick Polyurethane was used to reduce the friction be-tween the aluminum (AA1100) and the tools. Figure 2 shows the result of the FLC test. This curve is used to determine the maximum strain limits that the sheet can have when subjected to certain deformation levels. The curve line represents the possible values of the combinations of stain of the specimen that indicate signs of rupture start, the curve can be interpreted as a border between regions of failure and safety. The region above the curve is the region of failure or rupture. The region below the curve represents the safety region. This curve was obtained to be used in the simulation as a criterion of failure of the material and will also be used for the comparison with the results of the simulation with the different frictions attributed between the sheet and the tools. 


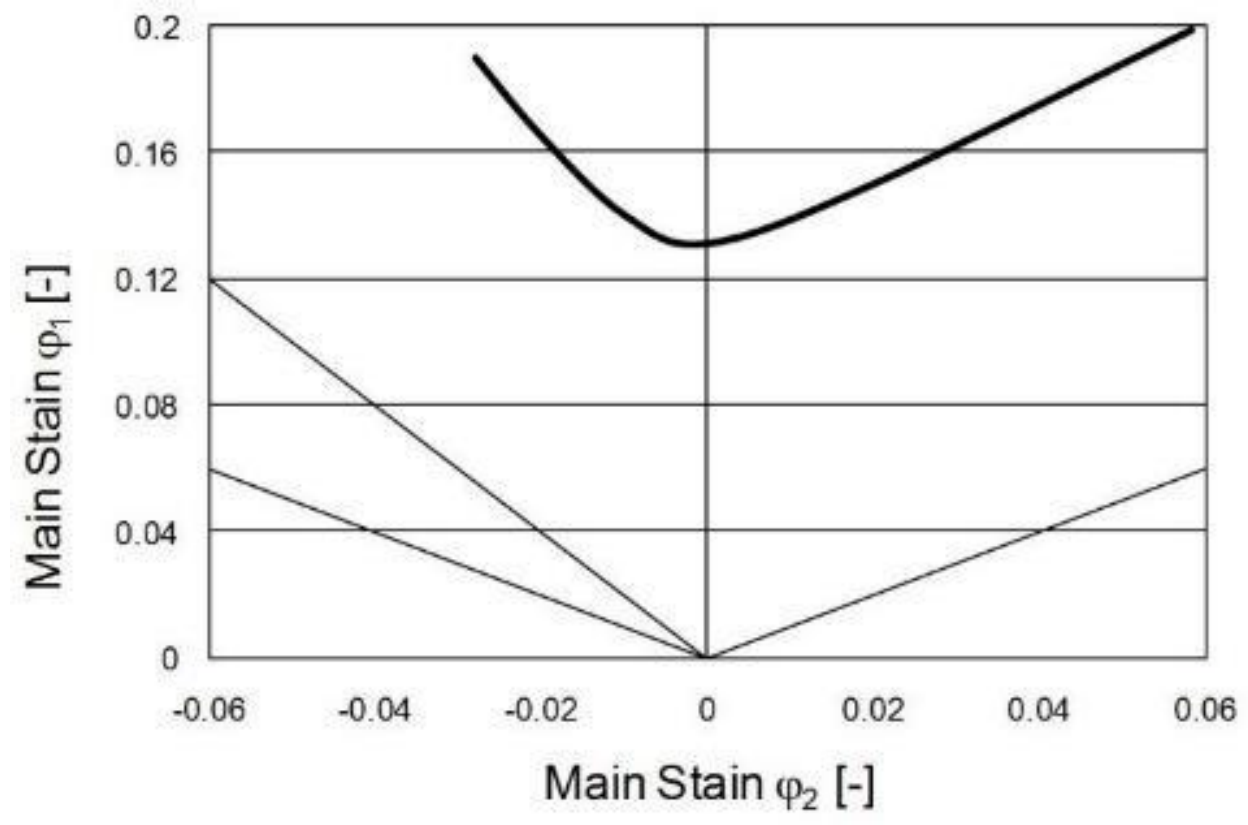

Figure 2: Forming Limit Curve of aluminum (AA1100).

\subsection{Analytical calculation of the maximum drawing force}

There are several equations that are used to calculate the maximum drawing force in the deep drawing process. These equations generally give limited information about the process or the material used because they are applied to simple geometries, or they make several simplifications that add uncertainty to the calculation. Some examples include the equations used to calculate the maximum force in a conventional stamping. These equations are used to estimate the strength of the press needed to draw a piece. Siebel and Panknin [13] developed an analytical model based on the elementary theory of plasticity. The model considers the main factors that contribute to the maximum force in the deep drawing of a cylindrical cup form. Figure 3 illustrates the parameters involved schematically. 


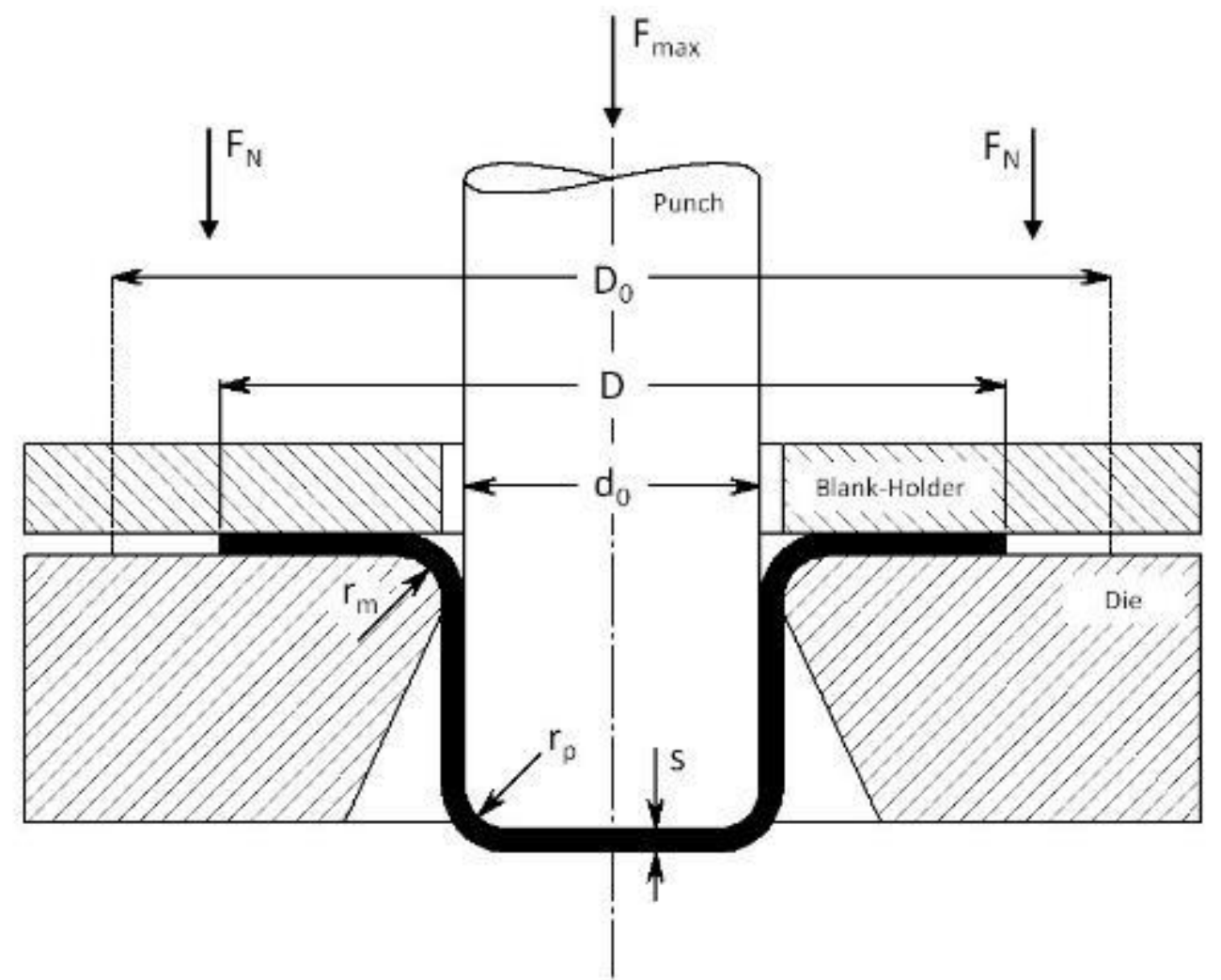

Figure 3: Schematic representation of a drawn cup [13].

The expressions for each drawing force are described below.

a) Ideal drawing force (Fid)

$$
F_{i d}=A_{0} \cdot k f_{m} \cdot \ln \frac{D}{d_{0}}
$$

where $\boldsymbol{A}_{\boldsymbol{o}}$ is the section cup area $\left(A_{0}=\pi \cdot d_{0} \cdot s\right)$ and $\boldsymbol{D}$ is the diameter of the flange for the maximum drawing force calculated by Siebel and Panknin (1956), which is represented by Equation 2.

$$
D=\left(0,77 \cdot \frac{D_{0}}{d_{0}}+0,23\right) \cdot d_{0}
$$

The maximum force, according to Siebel and Panknin [13], occurs when the punch has traveled approximately $30 \%$ of the total punch traveled by a deep drawing. In Equation 1, the medium yield stress $\boldsymbol{k} \boldsymbol{f}_{\boldsymbol{m}}$ is calculated by:

$$
k f_{m}=\frac{k f_{1}+k f_{2}}{2}
$$

where $k f_{1}$ is the yield stress of the sheet in the output of the die radius, and $\boldsymbol{k} \boldsymbol{f}_{2}$ is the yield stress of the outside diameter in the flange region. Because calculating the yield stress depends on the region, it is necessary to know how to calculate the strain. Thus, the strain $\varphi_{1}$ after the sheet is drawn through the radius of the die is the following:

$$
\varphi_{1}=\ln \left(\frac{\sqrt{D_{0}^{2}+d_{0}^{2}-D^{2}}}{d_{0}}\right)=\ln \sqrt{\beta_{0}^{2}+1-\beta^{2}}
$$

This strain can be calculated as a function of the limit drawing ratio $\boldsymbol{\beta}_{\boldsymbol{0}}$ and $\boldsymbol{\beta}$ as follows:

$$
\beta_{0}=\frac{D_{0}}{d_{0}}
$$


and

$$
\boldsymbol{\beta}=\frac{D}{d_{0}}
$$

The strain in the flange region $\varphi_{2}$ is calculated as the following:

$$
\varphi_{2}=\ln \frac{D_{0}}{d_{0}}
$$

The yield stress $\boldsymbol{k} \boldsymbol{f}_{\boldsymbol{1}}$ and $\boldsymbol{k} \boldsymbol{f}_{2}$ can be calculated using Equation 8, where $\boldsymbol{C}$ and $\boldsymbol{n}$ must be known and are determined according to the sheet material. Thus, $\boldsymbol{k} \boldsymbol{f}_{\boldsymbol{m}}$ can be determined.

$$
\boldsymbol{k f}=\boldsymbol{C} \cdot \varphi^{n}
$$

a) The friction force of the blank-holder in the flange region $\left(\boldsymbol{F}_{A P C}\right)$ is

$$
F_{A P C}=2 \cdot \mu \cdot F_{N} \cdot \frac{d_{0}}{D}
$$

where $\boldsymbol{F}_{\boldsymbol{n}}$ is the normal force of the blank-holder and $\boldsymbol{\mu}$ is the COF between the die and the sheet.

b) Friction force in the die radius $\left(\boldsymbol{F}_{A R}\right)$

$$
F_{A R}=\left(e^{\mu \cdot \frac{\pi}{2}}-1\right) \cdot\left(F_{i d}+F_{A P C}\right)
$$

In Equation 9, $\boldsymbol{\mu}$ represents the COF between the sheet and the die radius. The COF of Equation 9 should be different from that of Equation 10; however, in the present study, both were considered to be the same throughout the process.

c) Springback force $\left(\boldsymbol{F}_{\boldsymbol{R} E}\right)$

$$
F_{R E}=\pi \cdot d_{0} \cdot s \cdot k f_{1} \cdot \frac{s}{4 r_{m}}
$$

where $\boldsymbol{r}_{\boldsymbol{m}}$ represents the die radius.

Finally, to obtain the total force of the deep drawing though the Panknin [11] equations, it is necessary to add all the effects of the forces described above, i.e.:

$$
F_{\text {max }}=F_{i d}+F_{A P C}+F_{A R}+F_{R E}
$$

This method of calculation will be used in this work because the COF is used as an input parameter to determine the maximum drawing force.

\section{RESULTS AND DISCUSSIONS}

\subsection{Force vs. displacement measured curves}

As mentioned above, three sandpapers and four types of lubricants were applied. For each condition of friction, three valid tests were performed and the average curve between the three was taken as the representative curve for the sandpaper and lubricant. The resulting force and displacement measurements of the punch are shown in Figure 4, where they are grouped according to the sandpaper used and the applied lubricant. The lower right graph of Figure 4 shows the results for other lubricants with the 1200 sandpaper. 

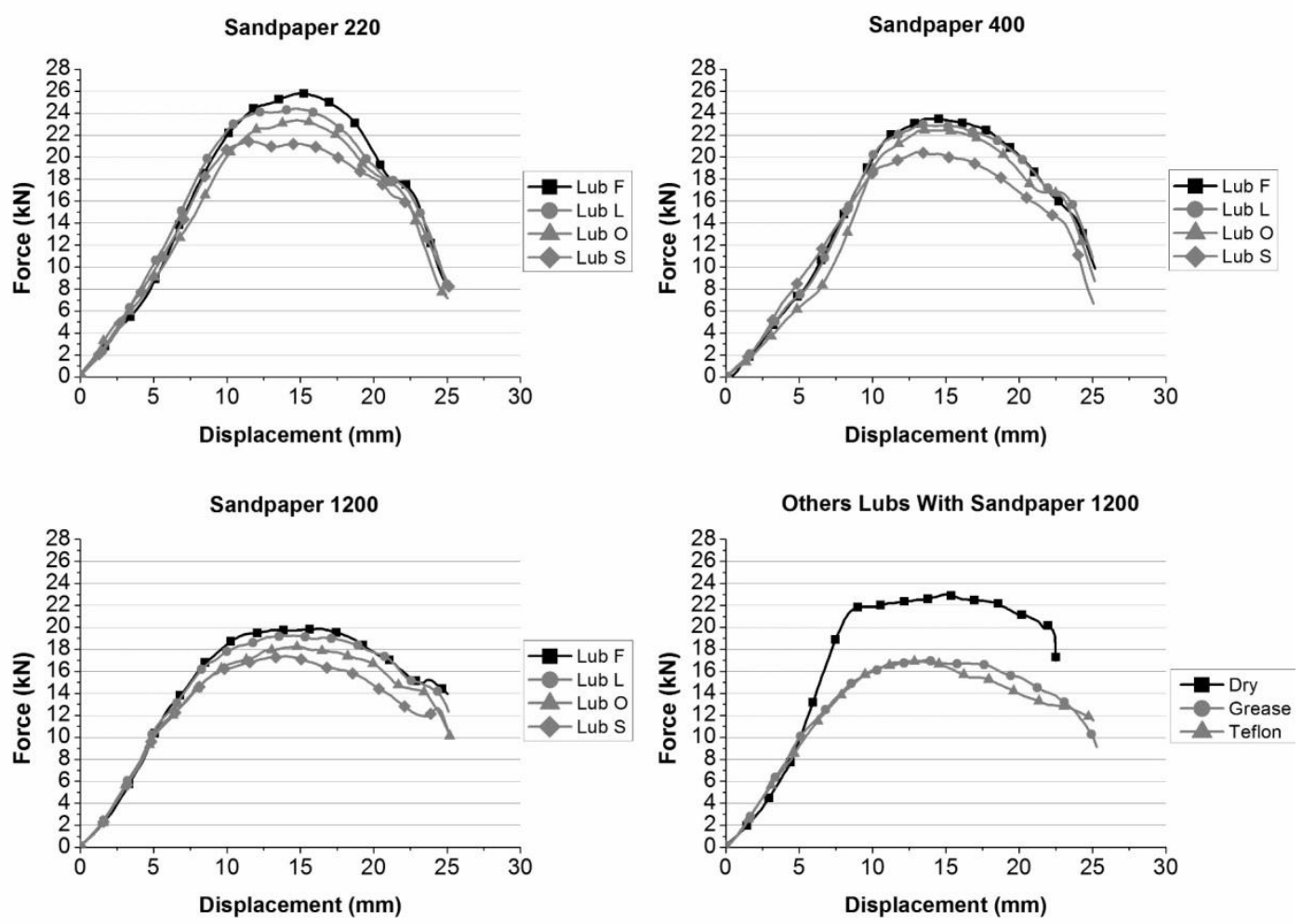

Figure 4: Graphs of force vs. displacement measured for each lubricant and sandpaper applied. The dry conditions, Teflon film and grease are shown as well.

For every graph in Figure 4, the maximum force for each curve that occurs after an approximately 15 $\mathrm{mm}$ displacement of the punch is obtained. After this, the force measured on the punch decays to zero, which corresponds to the end of the drawing where the desired final shape of the piece is obtained.

It is possible to observe that as the surfaces of the dies are more polished, there is a decrease in the sheet metal forming forces. This is due to the fact that as there is a decrease in the size of peaks of the surface, there is a corresponding decrease in the force necessary to make the sheet to move, because there will be less amount of peaks meeting and thus the lubricant will have more acting in the separation interface.

During the strain of a sheet metal the coefficient of friction is controlled by two different components, an adhesive force acting on the real areas of contact (Figure 5a) and a deformation force acting during the penetration of the roughening of the tool, which is harder, on the sheet, which is softer (Figure 5b).

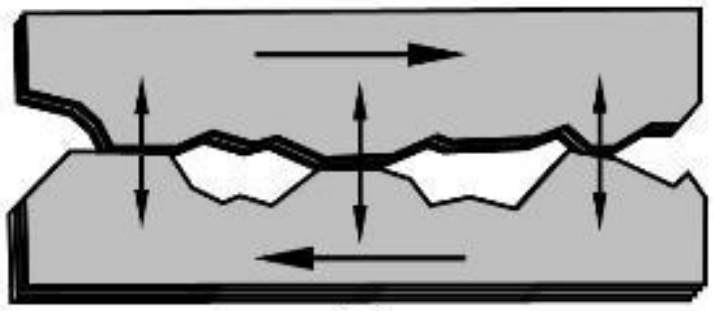

(a)

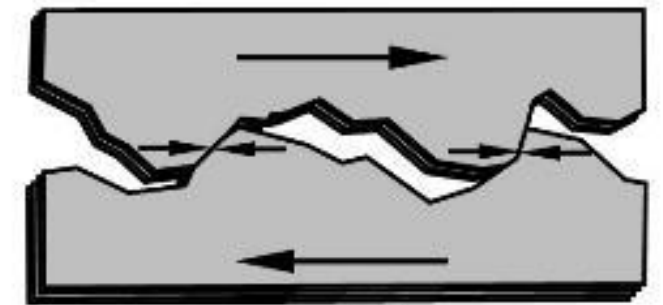

(b)

Figure 5: Schematic illustration of the components of the coefficient of friction present in metal / metal contact.

Another observation of figure 4 is that no matter what shape the surface has, the best lubricant performance will always be the same, that is, the one that generates less force in the sheet metal forming. In the graphs, that lubricant was the lub S, which under all conditions generated a lower sheet metal forming 
force. This is probably because the lubricant has additives (such as teflon particles, for example) that improve the ability to slip between surfaces and this will occur whenever the lubricant is able to remain between the contact surfaces. In the lubricants used, the chemical composition was not evaluated, as this was not the objective of the study.

Table 3 shows the values of the maximum forces obtained from the plots in Figure 4. The values are measured in $\mathrm{kN}$. It can be seen that the non-lubricated sheet metal forming had a lower force than when applying sandpapers 220 and 400 with some lubricants. This can be explained by the effect of adhesion of sheet material on the tools. When there is no lubrication at the materials interface, the aluminum tends to adhere to the dies and this happens early in the deformation, causing a peak of force. The adhered material must then be sheared for the stamping to continue. This can be seen in figure 4, on the dry graphic. After the adhered material has been sheared, the force does not increase as the material has flowed and itself functions as an interface lubrication. This condition may seem beneficial since it decreases the punch force, however adhesion of material will promote scratches on the sheet which is a surface defect. The adhered material will also make difficult the stamping of other parts in the same tooling in serial productions.

Table 3: Maximum force obtained from the tests.

\begin{tabular}{c|c|c|c|c|c|c|c}
\hline \multirow{2}{*}{ SANDPAPERS } & \multicolumn{7}{c}{ LUBRICANTS } \\
\cline { 2 - 8 } & F & L & O & S & TEFLON & GREASE & DRY \\
\hline 220 & 25.7 & 24.3 & 23.3 & 21.4 & - & - & - \\
\hline 400 & 23.4 & 22.4 & 22.9 & 20.4 & - & - & - \\
\hline 1200 & 19.8 & 19.2 & 18.2 & 17.3 & 16.9 & 16.9 & 22.9 \\
\hline
\end{tabular}

\subsection{Calculation of the COF with the Panknin equations}

The geometric parameters obtained by the Swift cup test tools are shown in Table 4. Figure 1 shows a crosssection of the tooling with the dimensions of each component.

Table 4: Geometric parameters of the tools used in the tests.

\begin{tabular}{l|l|l|l}
\hline \multicolumn{4}{c}{ GEOMETRIC PARAMETERS } \\
\hline Punch diameter & $\mathrm{d}_{0}$ & 50 & $\mathrm{~mm}$ \\
\hline Sheet thickness & $\mathrm{s}_{0}$ & 1 & $\mathrm{~mm}$ \\
\hline Blank diameter & $\mathrm{D}_{0}$ & 90 & $\mathrm{~mm}$ \\
\hline Die radius & $\mathrm{r}_{\mathrm{m}}$ & 6.5 & $\mathrm{~mm}$ \\
\hline
\end{tabular}

The maximum force obtained from testing the equations of Panknin [11] can be used to obtain the COF. Thus, Table 5 shows the results of the COFs for each sandpaper and lubricating oil. The blank holder force, Fn, was also measured and kept constant for all tests; its value was approximately $10 \mathrm{kN}$.

Table 5: COF obtained with the Panknin equations.

\begin{tabular}{c|c|c|c|c|c|c|c}
\hline \multirow{2}{*}{ SANDPAPERS } & \multicolumn{7}{|c}{ LUBRICANTS } \\
\cline { 2 - 8 } & $\mathbf{F}$ & $\mathbf{L}$ & $\mathbf{O}$ & $\mathbf{S}$ & TEFLON & GREASE & DRY \\
\hline 220 & 0.244 & 0.219 & 0.200 & 0.160 & - & - & - \\
\hline 400 & 0.202 & 0.182 & 0.192 & 0.140 & - & - & - \\
\hline 1200 & 0.127 & 0.113 & 0.089 & 0.067 & 0.056 & 0.056 & 0.192 \\
\hline
\end{tabular}




\subsection{Simulation methodology}

The specific objective of the numerical simulation is to reproduce the experimental study, evaluate the COF and compare the values of force versus displacement of the punch with the measured results.

To analyze the desired geometry, deep drawing eta/ DYNAFORM Version 5.6 with the LS-Dyna solver version 971 Finite Element software was used. Shell elements were used to define the material of the blank and the tools (punch, die and blank holder). Blanks were considered to be an elastic-plastic material, and the punch, die and blank holder were modeled as rigid tools. Figure 6 shows the construction of the entire assembly mounted on the FE software with the generated meshes and mesh refinement details in critical regions. The simulation was divided into three steps: first, the blank holder was moved up to the sheet; second, the blank holder applied a force of $10 \mathrm{kN}$; finally, the punch was moved $40 \mathrm{~mm}$, which caused the piece to be drawn. This value was specified to be the displacement obtained in experimental tests.

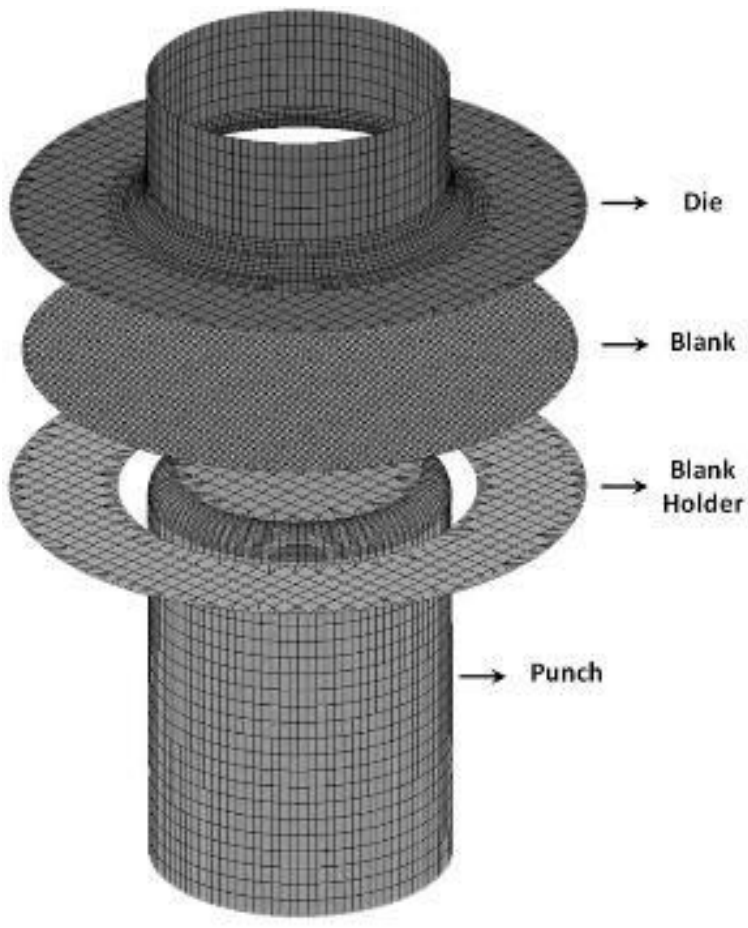

Figure 6: Assembly mounted on DYNAFORM to simulate the deep drawing processes.

\subsection{Results obtained through simulation}

The numerical simulation of the Swift tests was made with DYNAFORM, where the COF adopted for each simulation was obtained from the Panknin equations [11] and is shown in Table 5. Among all the simulations, the only parameter evaluated was the COF; all others were constant. Table 6 shows the results of the maximum forces obtained by simulation for all sandpaper and lubricants used.

Table 6: Maximum force obtained from DYNAFORM in kN.

\begin{tabular}{c|c|c|c|c|c|c|c}
\hline \multirow{2}{*}{ SANDPAPERS } & \multicolumn{7}{c}{ LUBRICANTS } \\
\cline { 2 - 8 } & F & L & O & S & TEFLON & GREASE & DRY \\
\hline 220 & 24.2 & 22.8 & 22.3 & 20.8 & - & - & - \\
\hline 400 & 22.3 & 21.5 & 21.8 & 20.0 & - & - & - \\
\hline 1200 & 19.4 & 18.6 & 18.1 & 17.2 & 16.9 & 16.9 & 21.8 \\
\hline
\end{tabular}

After obtaining the maximum forces, it was observed that the results from the simulation tend to deviate from the maximum forces measured in the Swift cup tests. Figure 7 shows this trend, where the vertical axis represents the distance percentage between the maximum forces measured and simulated, and 
the $\mathrm{x}$-axis shows the linearly increasing maximum force values.

Table 7: Value of the relationship between the maximum force measured and the deviation between the measurement and simulation results.

\begin{tabular}{c|c|c|c}
\hline LUBRICANTS & SANDPAPERS & $\begin{array}{c}\text { FORCE } \\
(\text { KN })\end{array}$ & $\begin{array}{c}\text { DEVIATION } \\
(\boldsymbol{\%})\end{array}$ \\
\hline Teflon & 1200 & 16.9 & 0.0 \\
\hline Grease & 1200 & 16.9 & 0.0 \\
\hline S & 1200 & 17.3 & 0.6 \\
\hline O & 1200 & 18.2 & 0.6 \\
\hline L & 1200 & 19.2 & 3.2 \\
\hline F & 1200 & 19.8 & 2.0 \\
\hline S & 400 & 20.4 & 2.0 \\
\hline S & 220 & 21.4 & 2.9 \\
\hline L & 400 & 22.4 & 4.1 \\
\hline O & 400 & 22.9 & 5.0 \\
\hline Dry & 1200 & 22.9 & 5.0 \\
\hline O & 220 & 23.3 & 4.5 \\
\hline F & 400 & 23.4 & 4.9 \\
\hline L & 220 & 24.3 & 6.5 \\
\hline F & 220 & 25.7 & 6.2 \\
\hline
\end{tabular}

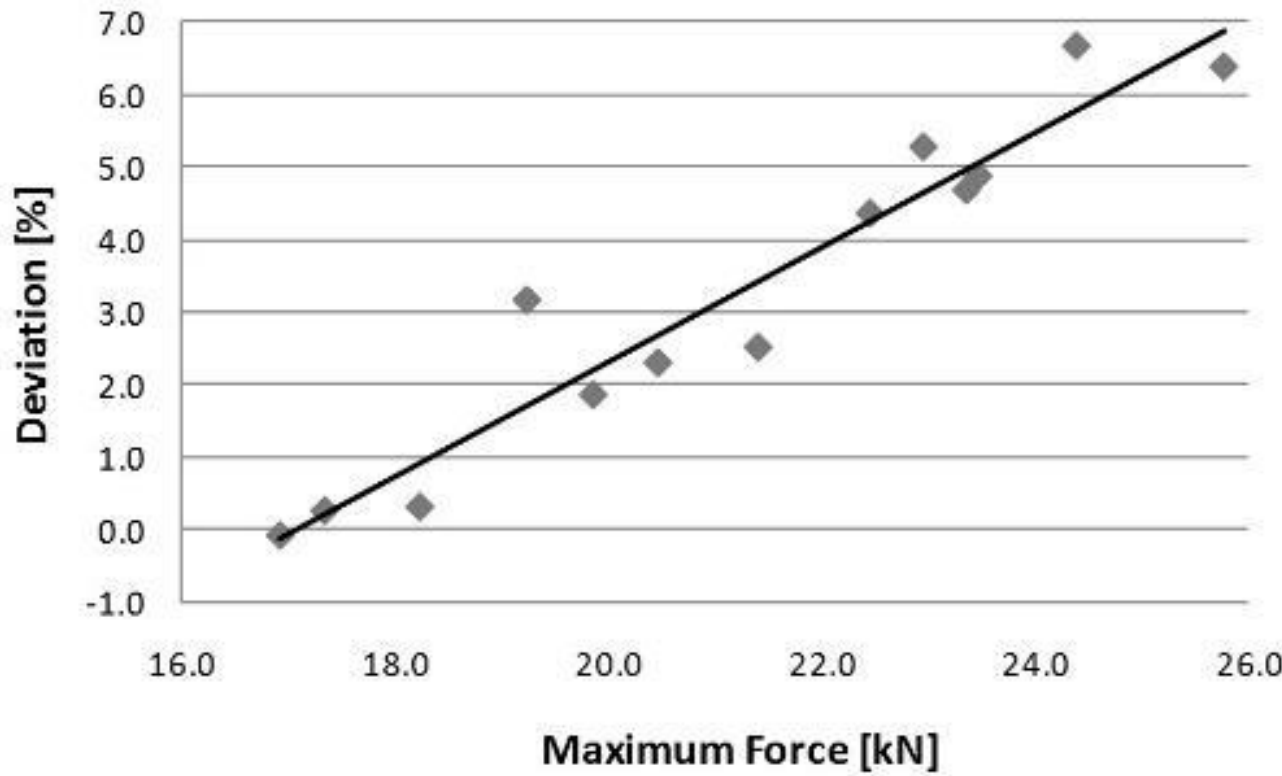

Figure 7: Relationship between the maximum force measured and the deviation between the measurement and simulation results.

The plot in Figure 7 shows that as the COF increases and, therefore, the maximum force increases, the deviation of the simulated values from measured values also increases. This suggests that as the friction forces increase in the simulation, the greater is the difference between the real deep drawing and the simulation. Another way to visualize this is using the graphs in Figure 8, which show the result of force vs. 
displacement for some COF, where the Swift test is compared with the simulation. The Table 7 show the value that is in the graph of Figure 7.

Fereshteh-Saniee and Montazeran [14] proposed a formulation to measure the maximum force of deep drawing and compare the results with the simulation using ANSYS with viscoelastic solid elements, shell elements and the Panknin [11] formulation. In the results, they conclude that the formulation of Panknin [11] and simulation with shell elements gives the best approximation of the real case; the error for the Panknin [11] formulations was $3.6 \%$ and $1.9 \%$ for the simulation. The sheet material was steel ASTM A619 with a COF of 0.15. Applying this error (3.6\%) in the maximum force measured with a Teflon film and recalculating the $\mathrm{COF}$, the result is 0.04 . This result is in agreement with the classical literature regarding the COF, which indicates that the Panknin [11] equations have a constant error. Thus, the gradual deviation of the maximum force measured and simulated may be associated with an error in the simulation methodology.
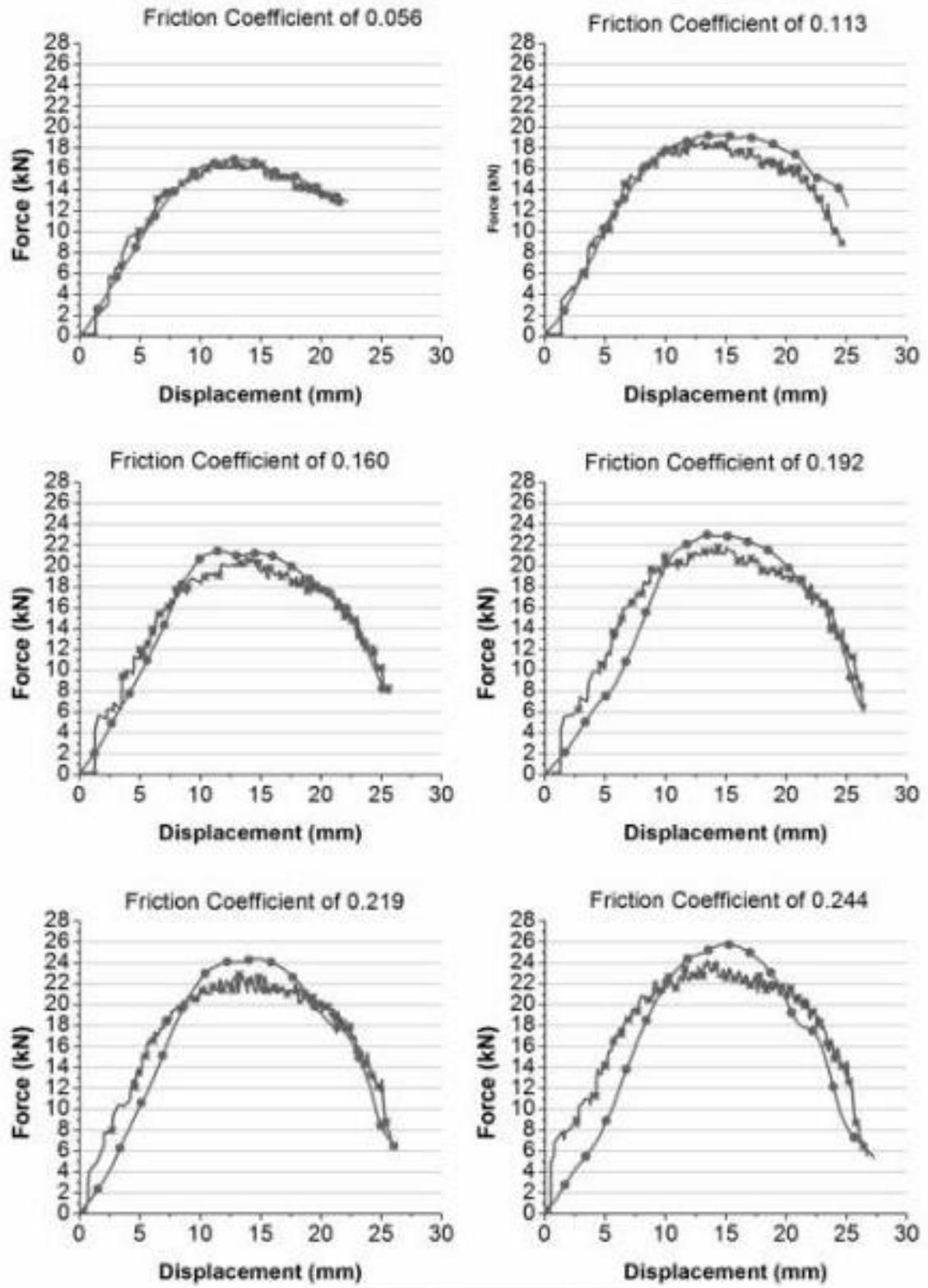

$\rightarrow$ - Simulated $-\mathrm{C}-$ Measured

Figure 8: Comparison between the simulation and measured results. 
In Figure 8, it can be observed that, as the COF increases, the distance between the simulated and measured curves also increases. Hao et al. [15], Lanzon et al. [16], Matuszak [17] and Darendeliler et al. [3] showed in their work that the COF in sheet metal forming is not a constant of the process, i.e., there is significant variation that may be the main source of error in deep drawing programs because they consider the friction to be constant.

The simulation demonstrates a difference in results compared to the real tests, and this difference tends to increase as the friction in the process increases. However, the maximum deviation that was observed between the simulated and real maximum force was $6 \%$, which, in terms of engineering, is acceptable. The simulation proved to be reasonable to predict the strength during the drawing. Figure 9 shows the strain of the piece according to the simulation for two friction conditions.

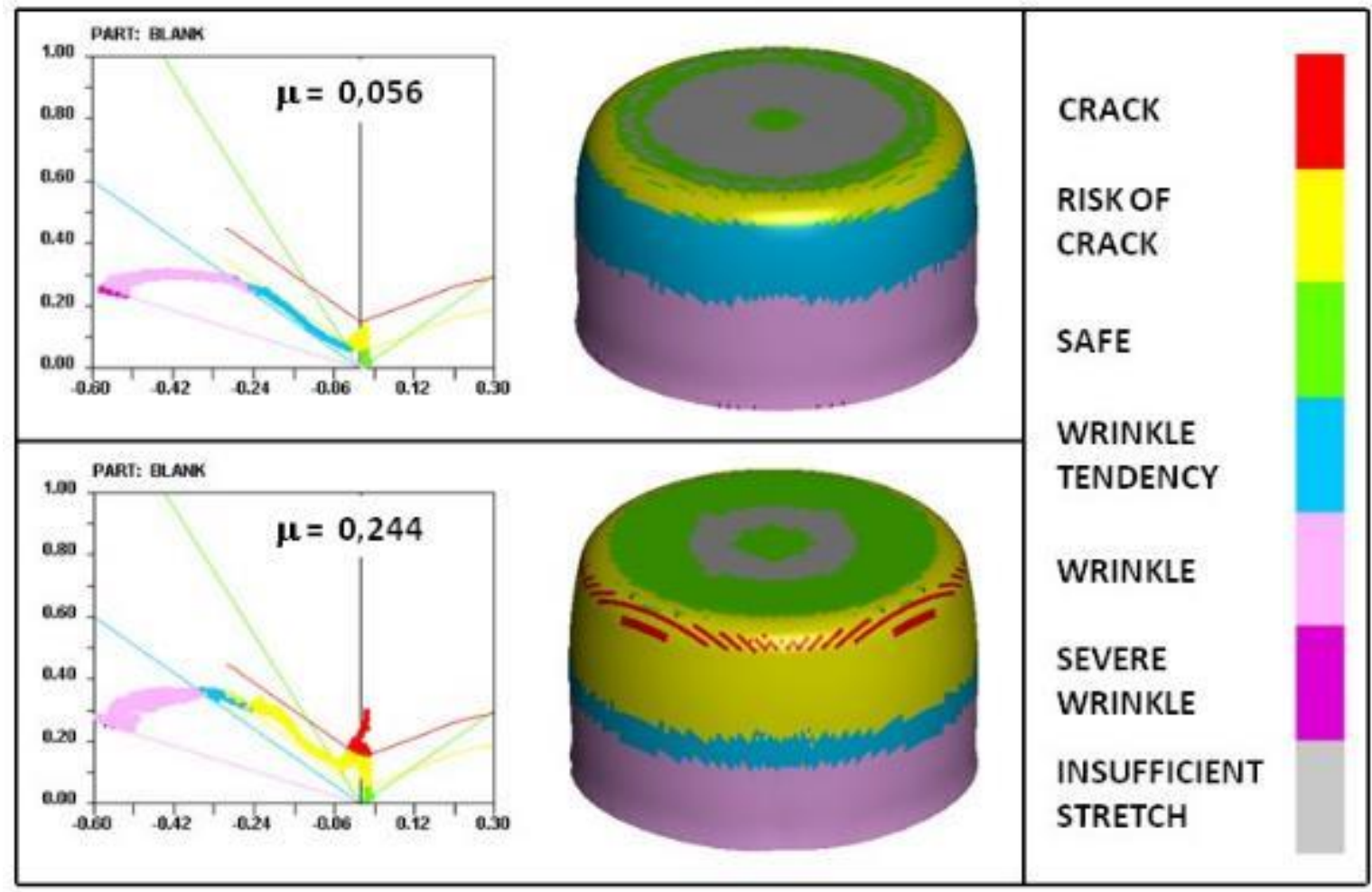

Figure 9: Results obtained from simulation for the minimum and maximum COF.

As can be seen, as the friction increases, the strain of the piece more closely follows the Forming Limit Curve (FLC), and the risk of the piece breaking prematurely increases. In fact, the strains in the real tests with greater friction were higher than the Forming Limit Curve. Note also that there is a large region at the lower edge of the piece where the simulation predicts a tendency to wrinkle, which remains the same for all friction values. However, wrinkling did not occur for the pieces drawn. Figure 10 shows a piece drawn where there was no wrinkle. 


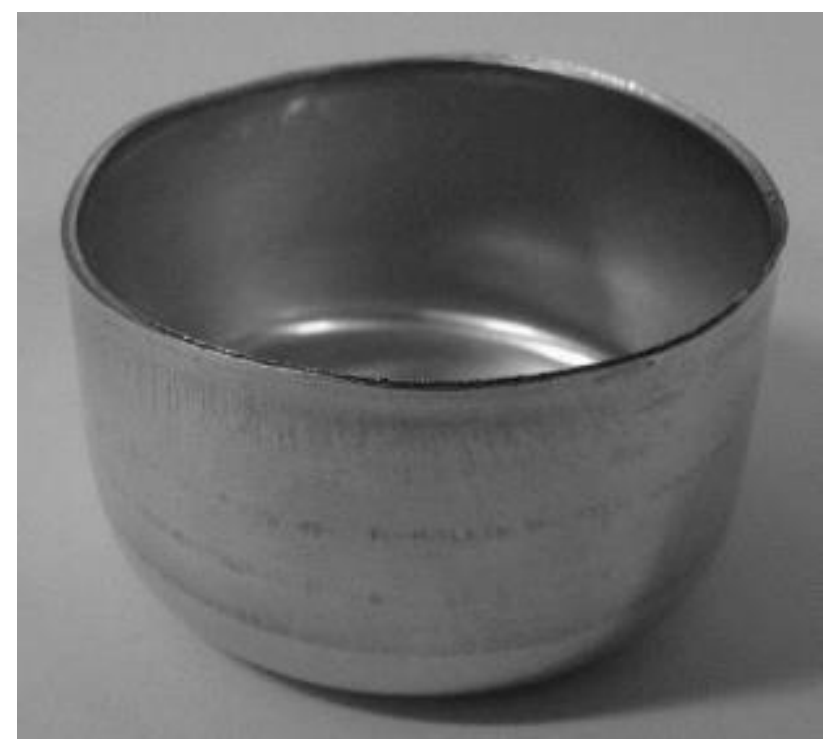

Figure 10: Piece drawn in which wrinkling does not occur.

Wrinkling did not occur in this piece because of the restrictions of the tools used to make the piece, and if these restrictions were relieved, the sheet would have wrinkled, which is shown in Figure 11. The drawing in Figure 11 was made with Teflon film, where there is a physical separation between the die and the sheet, which gives the internal stresses of the sheet freedom to act.

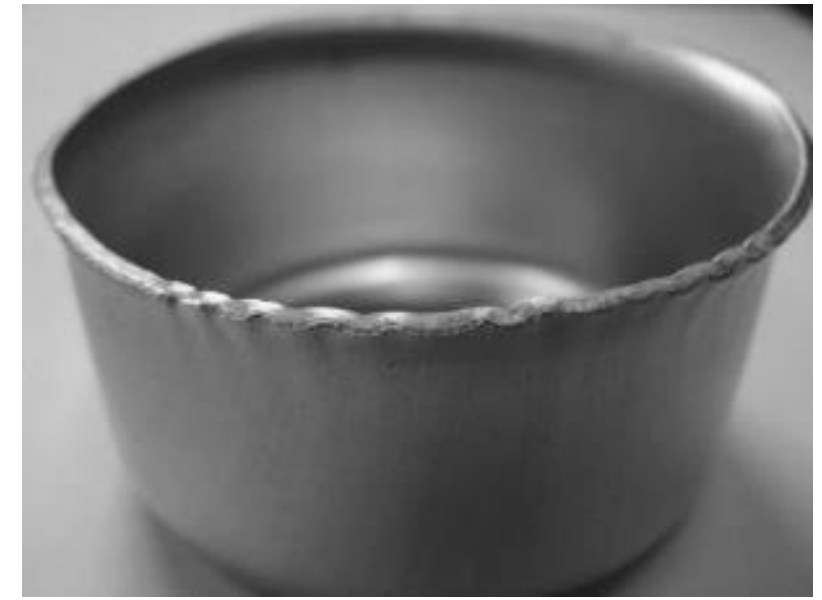

Figure 11: Piece drawing with a Teflon film.

During the tests, grease was also applied to examine the effect of this lubrication. The friction generated by the grease was almost equal to that generated by the Teflon, and in this case, there was also a visible tendency to wrinkle in the edges of the piece. This is shown in Figure 12. 


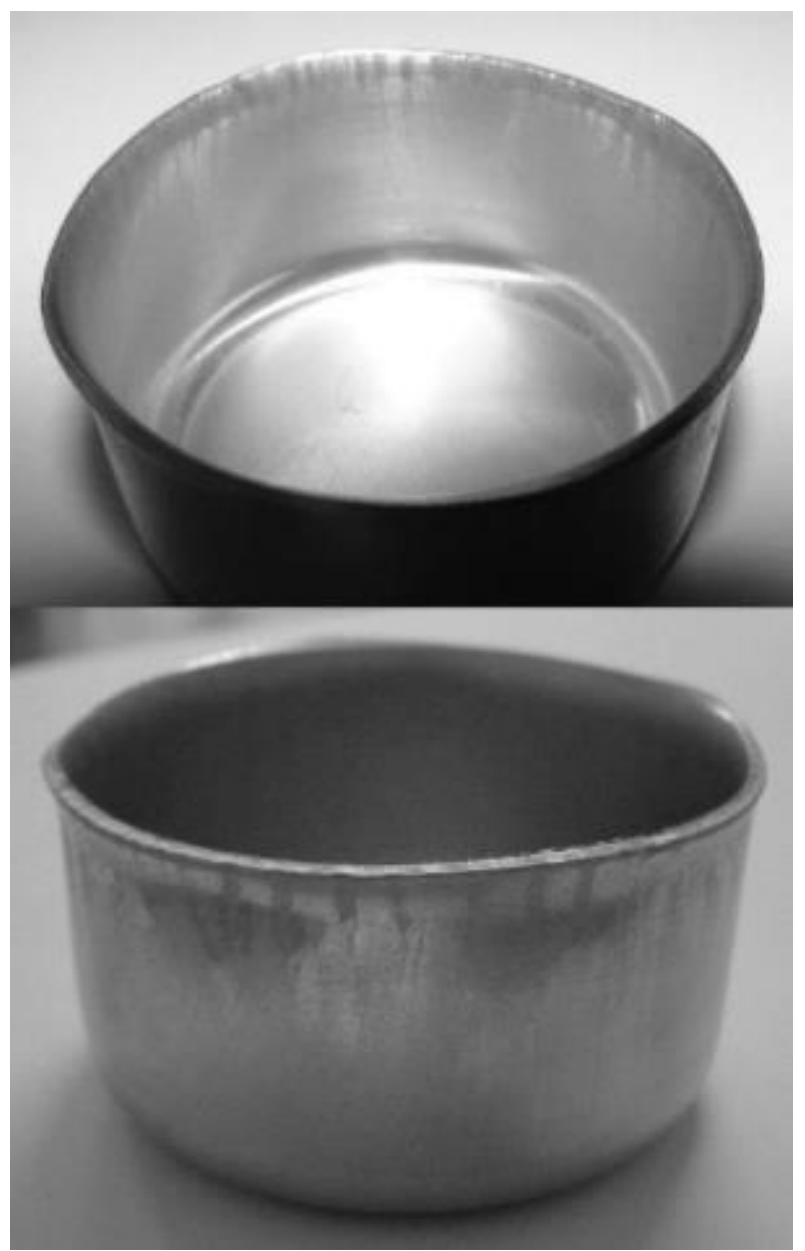

Figure 12: Piece drawing with grease lubricant.

In the blank drawn with lubricant $\mathrm{F}$ and 220 sandpaper, the strains were measured. The results are shown in Figure 13, where it is evident that the path of strains for the measured and simulated pieces are very close.

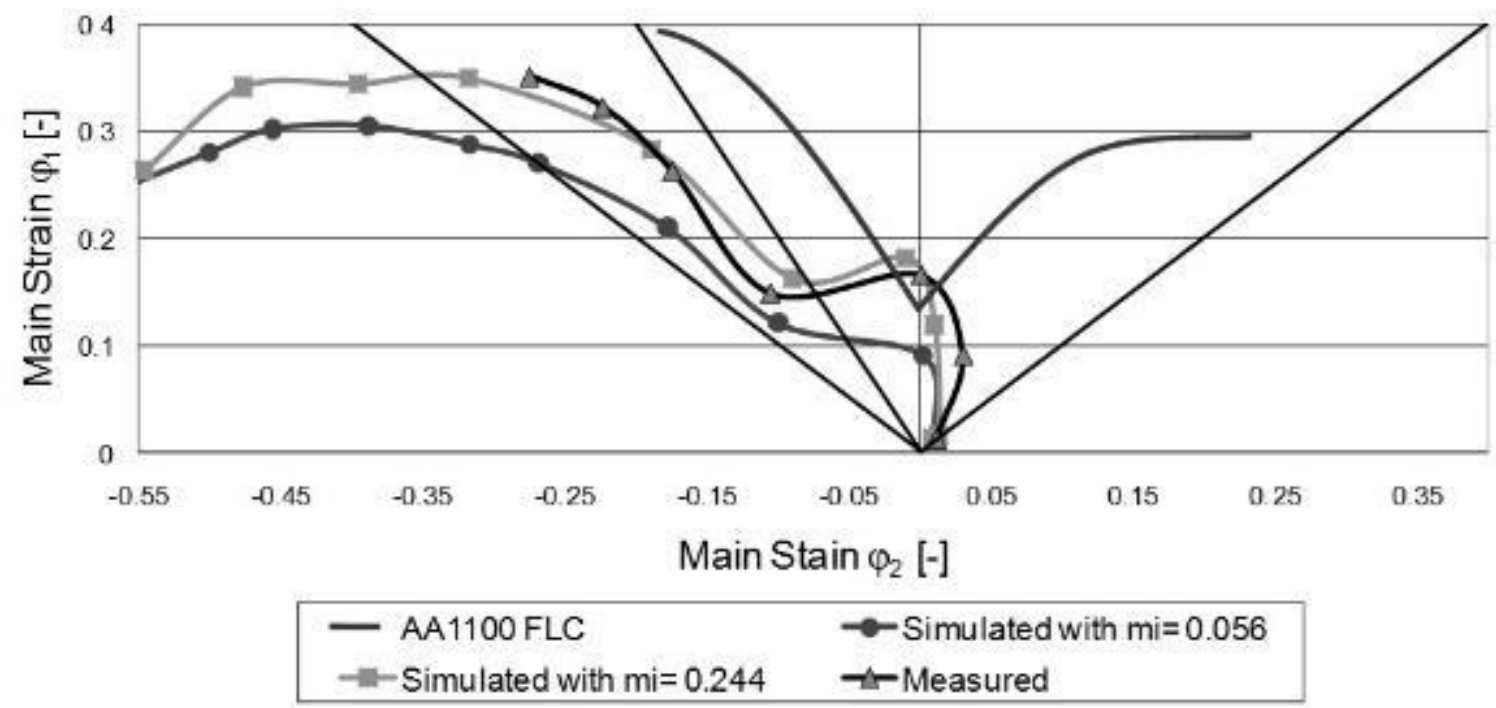

Figure 13: Comparison between the strain measured in the Swift test and those obtained by simulation. 
There are two important regions in the graph of the Forming Limit Curve to be discussed. The first is the region of main strain $\varphi_{1}$ in the vertical axis. In this region, the strain is simulated with higher friction, and the ones measured in the piece reached values above the FLC. This only occurred at that point of the FLC. This may be related to the way that the FLC is obtained through the Nakajima test. In these tests, eight test samples (TS) are cut with a standard geometry, and each test samples generates one strain point of the curve. These TS are then electrochemically printed with a circular mesh, placed in a tool that restricts the movement of the TS and forced against a punch until a crack forms. Because the TS are restricted by the blank holder and there is no relative motion between them, the TS are only stretched. After the tests, the circles close to the crack are measured to generate points in the FLC. Thus, the FLC is not generated by the rupture of the material, but only by localized necking. In terms of design it is beneficial because the curve includes a safety factor, i.e., all strains that are below the curve will be in a secure region. Therefore, in this region where only the main strain $\varphi_{1}$ exists, if the material is above the FLC, it does not mean that the piece will crack. This happened to the drawing of the piece with maximum COF.

However, using Figure 13, reducing the COF between the tools and sheet drastically decreased the main strain $\varphi_{1}$. This can be done easily with a good finish on the tools associated with a good lubrication.

The other region of the graph in Figure 13 that is important to note is the main strain $\varphi_{2}$ in the negative $\mathrm{x}$-axis. These strains showed very high values, which indicates that a large region will suffer from wrinkling. Measurements made on the piece do not reach values that are so high because it is difficult to measure the deformation near the edge of the cup. However, with the use of Teflon, the wrinkle on the edge of the cup was observed, and the strains provided by DYNAFORM are very close to the true measured strains.

\section{CONCLUSIONS}

Based on the results obtained in this study, some conclusions can be made:

The methodology studied here proved to be very efficient for predicting the COF that is needed in the input data of the simulation.

As there is an increase in the maximum force due to surface conditions imposed on the tooling, there is a progressive increase in the contribution of frictional forces, which can cause premature rupture of the piece. On the other hand, if the friction is greatly reduced between the sheet and the tools, the material may have unwanted wrinkles.

The simulation using the software DYNAFORM presents good agreement with the Swift cup tests, but because there is an increase of the frictional forces and, therefore, the COF, the software has a tendency to deviate from a real drawing. This is probably because the software considers the friction to be constant throughout the process, and studies of COF measurements indicate that this is not true.

Through the simulations and measurements of the strains produced in the piece, it was observed that, for most friction conditions, there were strains above the Forming Limit Curve (FLC), but the piece did not crack. This is because of the way the FLC is obtained. In the Nakajima tests, the measurements of the circular mesh that are electro-chemically printed in the sheet never rupture the test sample, thus, the FLC is positioned just below the actual capacity of the material.

The results that have been shown here are valid for the geometry and material specified. It would be interesting for future studies to test the methodology of more complex geometries and other materials.

\section{BIBLIOGRAPHY}

[1] LEE B.H., KEUM Y.T., WAGONER R.H. "Modeling of the friction caused by lubrication and surface roughness in sheet metal forming”, Journal of Materials Processing Technology, v. 130, pp. 60-63, 2002.

[2] CERETTI E., FIORENTINO A., GIARDINI C. "Process parameters influence on friction coefficient in sheet forming operations", International Journal of Material Forming, v. 1, pp. 1219-1222, 2008.

[3] DARENDELILER H., AKKOK M., YUCESOY C.A. "Effect of variable friction coefficient on sheet metal drawing”, Tribology International, v. 35, n. 2, pp. 97-104, 2002.

[4] KIM H., SUNG J.H., SIVAKUMAR R., ALTAN T. Evaluation of stamping lubricants using the deep draw-ing test, International Journal of Machine Tools and Manufacture, v. 47, n. 14, pp. 2120-2132, 2007. 
[5] MURAKAWA M., TAKEUCHI S. "Evaluation of tribological properties of DLC films used in sheet forming of aluminum sheet", Surface and Coatings Technology. v. 163, pp. 561-565, 2003.

[6] GUILLON, O., ROIZARD, X., BELLIARD, P. "Experimental methodology to study tribological aspects of deep drawing - application to aluminium alloy sheets and tool coatings", Tribology International, v. 34, n. 11, pp. 757-766, 2001.

[7] FRATINI L., CASTO S. LO, VALVO E. L.O., "A technical note on an experimental device to measure friction coefficient in sheet metal forming", Journal of Materials Processing Technology, v. 172, n. 1, pp. 1621, Feb 20, 2006.

[8] HAO S., KLAMECKI B. E., RAMALINGAM S., "Friction measurement apparatus for sheet metal forming”, Wear, v. 224, n. 1, pp. 1-7, Jan, 1999.

[9] LOVELL M., HIGGS C. F., DESHMUKH P., et al., "Increasing formability in sheet metal stamping operations using environmentally friendly lubricants", Journal of Materials Processing Technology, v. 177, n. 1-3, pp. 87-90, Jul 3, 2006.

[10] ANDREASEN J. L., OLSSON D. D., CHODNIKIEWICZ K., et al., "Bending under tension test with direct friction measurement", Proceedings of the Institution of Mechanical Engineers Part B-Journal of Engineering Manufacture, v. 220, n. 1, pp. 73-80, Jan, 2006.

[11] PANKNIN W. "Die Grundlagen des Tiefziehens im Anschlag unter besonderer Berücksichtigung der Tiefziehprüfung", Bänder Bleche Rohre, v. 2, n. 4, pp. 133-143, 1961.

[12] MIELNIK E.M. Metalworking Science and Engineering. New York, McGraw-Hill, 1991. 976p.

[13] SIEBEL, E., PANKNIN, W. "Das tiefziehens im anschlag. Werkstattstechnik und maschinenbau", v. 46, n. 7,pp. 321-326, 1956.

[14] FERESHTEH-SANIEE F., MONTAZERAN M.H. "A comparative estimation of the forming load in the deep drawing process", Journal of Materials Processing Technology, v. 140, pp. 555-561, 2003.

[15] HAO, S., KLAMECKI, B.E., RAMALINGAM, S. "Friction measurement apparatus for sheet metal forming", Wear, v. 224, n. 1, pp. 1-7, 1999.

[16] LANZON J.M., CARDEW-Hall M.J., HODGSON P.D. Characterising frictional behaviour in sheet metal forming, Journal of Materials Processing Technology, v. 80, n. 1, pp. 251-256, 1998.

[17] MATUSZAK, A. "Factors influencing friction in steel sheet forming", Journal of Materials Processing Technology, v. 106, n. 1-3, pp. 250-253, 2000.

\section{ORCID}

Luis Fernando Folle https://orcid.org/0000-0002-3829-496X

Lirio Schaeffer

https://orcid.org/0000-0002-3427-2405 